\title{
O DESENVOLVIMENTO DO CONHECIMENTO PEDAGÓGICO DO CONTEÚDO DE SEXUALIDADE NA VIVÊNCIA DAS PROFESSORAS
}

\section{The development of the pedagogical content knowledge about the sexuality in teachers' practice}

\author{
Mirian Pacheco Silva \\ Washington Luiz Pacheco de Carvalho"
}

\begin{abstract}
Resumo: Neste artigo, relatamos uma investigação sobre o desenvolvimento do "conhecimento pedagógico do conteúdo" de Sexualidade entre professoras que trabalham com essa temática. Através da utilização do método fenomenológico foram realizadas entrevistas individuais com três professoras do Ensino Fundamental, que trabalham na rede municipal de ensino de Uberlândia. A partir da análise dessas entrevistas, foi possível apontar algumas conclusões a respeito do desenvolvimento profissional de professores e sua relação com um ensino efetivo.
\end{abstract}

Unitermos: Educação Sexual, Conhecimento Pedagógico do Conteúdo, Fenomenologia

Abstract: This article presents the results of a survey carried out to understand the development of "pedagogical content knowledge" in the teaching of sexuality amongst teachers who work with this topic. Using the phenomenological approach, individual interviews were carried out with three female Elementary School teachers working in Uberlândia municipal school system, in Minas gerais State, Brazil. By analyzing these interviews, it was possible to reach some conclusions regarding teachers' professional development and its relationship with effective teaching.

Keywords: Sexual Education, Pedagogical Content Knowledge, Phenomelogical

\section{Introdução}

Por ser inerente ao ser humano, a sexualidade tem sido objeto de estudos e pesquisas em diversas áreas do conhecimento como: Psicologia, Biomédica, Economia, Sociologia, História e, principalmente, Educação. Esse fato não é novo. Desde os primórdios, quando a participação do homem no processo de reprodução era desconhecida e a prática sexual acontecia de forma natural, a temática da sexualidade já exercia fascínio nos estudiosos. Aspectos tais como a menstruação e a maternidade eram cercados de mistério, magia, feitiçarias e explicações religiosas. Alguns pesquisadores como Chauí (1985), Ribeiro (1995), Sayão (1997) e Werebe (1998), entre outros, relatam o desenvolvimento de vários projetos e a realização de várias pesquisas e experiências na área da sexualidade, durante todo o século XX. Entretanto, foi somente no final da década de 1990, com a implementação dos Parâmetros Curriculares Nacionais (PCN), que a entrada da Educação Sexual na escola, alcançou resultados normativos culminando com o desenvolvimento de projetos e aulas de Educação Sexual.

Sobre as aulas de Educação Sexual, Vitiello (1994, p. 209) afirma que, idealmente, devem ser ministradas por meio de metodologias participativas e dialógicas, baseadas na realidade sociocultural, desenvolvida com criatividade, intimista e lúdica. Segundo Lorencini-Júnior (1997, p. 95), as aulas de Educação Sexual podem ser consideradas como um "processo de transformação e mudança, que parte de um projeto coletivo e atinge os indivíduos, cada qual com sua busca

* Mestre em Educação para a Ciência pela Faculdade de Ciências - Unesp - Campus de Bauru - SP. Doutoranda em Educação pela Unicamp.E-mail:mirianps@unicamp.br

**Professor Adjunto do Depto. de Física e Química - Feis/Unesp de Ilha Solteira. Professor e Orientador no Programa de Pós-graduação em Educação para a Ciência - FC/Unesp de Bauru -SP. E-mail: washcar@fqm.feis.unesp.br 
particular do(s) sentido(s) da sexualidade”. Porém, nem todos os professores estão preparados para trabalhar com a Educação Sexual na escola. Conforme Barcelos et al. (1996, p. 151) "os educadores, em sua maioria, continuam tratando o assunto apenas nos aspectos biológicos, ou no máximo, convidam um palestrante médico para isso". Esse despreparo para trabalhar com as questôes da sexualidade na escola, apresentado pelos professores, pode ter origem numa educação familiar anti-sexual e opressora que eles receberam e, também, na sua formação acadêmica inicial em que há pouca discussão sobre essa temática. Entretanto, mesmo sem ter preparo para trabalhar com a sexualidade, alguns professores a estão abordando em suas disciplinas.

Diante de tal fato, pretendemos neste artigo, apresentar os resultados de uma pesquisa realizada durante o mestrado, financiada pela Fapesp, que teve como objetivo investigar, através dos discursos das professoras que atuam no Ensino Fundamental da rede municipal de ensino, o desenvolvimento do "Conhecimento Pedagógico do Conteúdo" de sexualidade, buscando compreendê-lo enquanto fenômeno. O "Conhecimento Pedagógico do Conteúdo" é entendido por Shulman (1986, p. 9) como um conhecimento que "vai além do conhecimento da disciplina, por si, para uma dimensão do conhecimento da disciplina para o ensino". Para constituir os dados, realizamos nove entrevistas com três professoras graduadas em Letras, Biologia e História, responsáveis por ministrar as disciplinas de Português, Ciências e Orientação para a Vida. Essas professoras atuavam no Ensino Fundamental da rede pública de ensino, cumprindo uma carga horária entre 20 e 40 horas semanais e foram denominadas na pesquisa de Ana, Lia e Isa. A quantidade de entrevistas com cada professora aconteceu de acordo com a manifestação pessoal do fenômeno. Além disso, a duração de cada entrevista variou de 50 minutos, quando ocorreram no horário de módulo, e de duas horas, quando aconteceram fora do horário de trabalho, por opção das professoras. Para a análise dos dados aplicamos o método fenomenológico. Martins e Bicudo (1989, p. 22) afirmam que a Fenomenologia busca o estudo do fenômeno, e o sentido que a palavra fenômeno adquire para a Fenomenologia está relacionado "àquilo que se manifesta, é tudo o que aparece ou se revela por si mesmo." O fenômeno existe a partir do sujeito que o interroga e que procura ver além da aparência. É o que se manifesta à consciência, portanto, só existirá um fenômeno se existir um sujeito no qual ele se situa. Carvalho (1991, p. 48) salienta que "a análise fenomenológica, busca a compreensão daquilo que está sendo interrogado e não está interessada em universalidades ou explicaçôes”. Desse modo, o autor ressalta que, "quando o pesquisador busca a compreensão de um dado fenômeno ele pode, se assim desejar, fazê-lo com ênfase a uma perspectiva”.

\section{Os discursos e os momentos de análise}

De posse das entrevistas percorremos o seguinte caminho:

Primeiramente, realizamos a análise ideográfica. Nessa etapa o pesquisador necessita ler atenciosamente o relato, do início ao fim, ou seja, o pesquisador deve colocar-se no lugar do sujeito para chegar ao sentido mais geral do que foi relatado. Depois de apreender o sentido, o pesquisador faz nova leitura com a intenção de destacar as unidades de significado. Essas unidades, que são recortes eleitos como significativos, podem variar de pesquisador para pesquisador dependendo da sua interrogação. Após extrair as unidades de significado, o pesquisador identifica convergências entre elas, agrupando-as, e depois realiza a transformação do discurso ingênuo em um discurso próprio da área de pesquisa. No momento seguinte, são obtidas as expressóes sintéticas que revelam a essência dos agrupamentos das unidades de significado. Assim, chega-se a uma síntese dos dados obtidos no discurso. A partir dessa síntese, passa-se para o momento da análise nomotética. Nesta tem-se uma reflexão e aproximação à compreensão 
do fenômeno interrogado a partir da síntese que foi levantada. É um movimento de passagem do individual para o geral, baseado nas realizações conseguidas na análise ideográfica.

\section{Momentos da Análise Ideográfica}

A partir das unidades de significado retiradas das entrevistas, realizamos a transformação do discurso ingênuo e chegamos às expressões sintéticas.

Expressão sintética do discurso da professora Ana:

- Os pais têm dificuldade de realizar Educação Sexual

- Enfrenta e supera dificuldades para a construção do seu ensino

- É preciso ganhar a confiança dos alunos

- Aprende-se com o aluno

- Aluno se interessa pelo tema

- Finalidade das aulas: prevenção

- A prática da professora é refletida

- Formas de ensinar: busca constante da professora

- Discutir a sexualidade é uma necessidade do aluno

- Conteúdo é interdisciplinar

- Os alunos confiam na professora

- Educação Sexual exige responsabilidade

- Sexualidade resolvida: fator essencial

Expressão sintética do discurso da professora Lia

- Interesse do aluno aumenta com o tempo

- A amizade entre professora e alunos é fundamental

- A professora também aprende enquanto ensina

- Trabalhar sexualidade é diferente de trabalhar os outros conteúdos

- Educação Sexual: escola versus sociedade

- É importante fazer uma seleção de material didático

- A questão de gênero subjaz a questão sexual

- Aluno busca modelo ou contra-modelo na professora

- Aprende-se com os erros

- A professora busca a formação continuada

- Avaliação: ocorre constantemente

Expressão sintética do discurso da professora Isa

- A professora tem que estar e se mostrar disposta

- Adolescente é mal informado, é confuso e tem medo

- Planejamento das aulas: atividade do dia-a-dia

- Existe reflexão sobre a realidade dos alunos

- Conteúdo: é necessário adequar às necessidades dos alunos

- Cria-se um ambiente de confiança e seriedade nas aulas

- Valoriza-se o uso de material didático e das estratégias de ensino

- A professora utiliza estratégias variadas para ensinar o conteúdo 
- É importante construir um discurso único com os outros professores

- As aulas são constantemente avaliadas

- A sexualidade é trabalhada apesar das dificuldades

- A professora é modelo para o aluno

\section{Momentos da Análise Nomotética}

A partir das expressões sintéticas encontradas no momento da análise ideográfica, realizamos uma reflexão na busca de uma aproximação à compreensão do fenômeno interrogado: desenvolvimento do "Conhecimento Pedagógico do Conteúdo" de sexualidade e, assim, chegamos no momento da análise nomotética. Essa análise "é feita com base na análise das divergências e convergências expressas pelas unidades de significado, estando vinculada, ainda, a interpretaçōes que o pesquisador faz para obter cada uma dessas convergências ou divergências" (GARNICA, 1997, p. 117). Tal momento permitiu-nos constituir três categorias que revelam indicadores de como o desenvolvimento acontece. São elas: Família, que aborda a questão da repressão, do constrangimento e dos valores; Escola, que discute sobre alunos, dificuldades, planejamento, conteúdo, formação contínua e avaliação; e, por último, Sociedade, que aborda a questão de modelos e implicações.

\section{Familia: repressão, constrangimento, valores...}

Repressão - A questão da repressão aparece no discurso das entrevistadas. As professoras acreditam que, mesmo tendo a consciência de que seus filhos já estão praticando a vida sexual, os pais evitam oferecer métodos contraceptivos, visto que isso significa romper com alguns tabus existentes na sociedade, como o da virgindade e do casamento.

Constrangimento - Os discursos revelam que para as professoras os pais não discutem sobre sexualidade com os filhos porque não foram preparados para isso e ficam constrangidos. Então preferem dizer que não têm tempo e deixam essa tarefa para a escola. Alguns pais tentam romper com essa situação e, na tentativa de justificar a ausência do diálogo, compram livros e revistas para os filhos, acreditando que essa é uma forma de Educação Sexual.

Valores - Todos os discursos apontam as professoras reconhecendo que cada família tem seus próprios valores e os repassam para os filhos. Juntamente com esses valores as famílias acabam repassando também preconceitos, tabus e mitos. Assim, em uma mesma sala de aula, uma professora tem que lidar com diferentes valores e, ao mesmo tempo, trabalhar os preconceitos que surgem no grupo com a preocupação de que o reflexo das suas aulas atingirá a sociedade como um todo.

\section{Escola: alunos, dificuldades, planejamento, conteúdo, formação contínua e avaliação}

Alunos - As convergências entre os vários discursos mostram que, diante das atitudes dos alunos, as professoras foram descobrindo que para ter eficácia nas aulas é necessário extrapolar a relação normalmente estabelecida entre professores e alunos. De início, é preciso ganhar a confiança deles, pois o conteúdo da sexualidade mexe com o "eu" de cada um. Ele precisa falar e ser ouvido para conseguir refletir sobre seus próprios problemas. Elas perceberam o quanto tais problemas interferem na vida, no ensino e na aprendizagem e contaram que, às vezes, o aluno quer simplesmente falar sobre algo que está acontecendo na sua vida para desabafar. Falando, ele se sente aliviado e participa da aula. Para elas, ouvir o aluno é fundamental para estabelecer um vínculo afetivo e criar amizade. 
Dificuldades - Os discursos mostram que as professoras enfrentam muitas dificuldades para a construção do ensino de sexualidade. Inicialmente, elas precisam superar o constrangimento de falar sobre esse assunto e, também, elaborar estratégias para lidar com o constrangimento dos alunos. Além do constrangimento, as professoras se deparam com a resistência deles ao conteúdo. Elas aprenderam que essa resistência é vencida com o tempo, na medida em que vai aumentando o interesse do aluno pelo conteúdo. Elas, também, aprenderam que precisam lidar com os tabus que surgem no grupo durante uma discussão, sem impor uma única forma de pensar. Outra dificuldade que é ressaltada na convergência dos discursos é a questão da necessidade de preparar aulas que atendam aos interesses de cada turma. As professoras descobriram que cada turma tem interesses diferentes dependendo da idade, da educação recebida na família, das vivências de cada aluno. Esse fato exige que elas preparem aulas diferenciadas e implica maior tempo de preparação das aulas, maior conhecimento de conteúdo e de estratégias que se adequem a cada conteúdo e a cada turma, além de maior envolvimento do professor com o conteúdo.

Planejamento - Os discursos mostram que as professoras têm uma grande preocupação em adequar o conteúdo às necessidades dos alunos. Uma das formas que elas encontraram foi utilizar estratégias e dinâmicas para conhecerem as idéias prévias que eles têm sobre sexualidade. Assim, elas elaboram o planejamento das aulas e vão modificando-o de acordo com as atividades que surgem no dia-a-dia da sala de aula, pois o conteúdo não é ensinado em uma seqüência. Pelo contrário, as professoras vão trabalhando com os temas que surgem nas aulas e, por isso, estão constantemente replanejando. Elas valorizam o uso do material didático e fazem uma seleção de quais são os mais adequados ao conteúdo que será ensinado. Como a escola não dispõe de muitos recursos pedagógicos, na maioria das vezes, são elas mesmas quem constroem o material utilizando sua criatividade. Além disso, todos os discursos apontam que as professoras atribuem um grande significado à questão do respeito com os conteúdos ensinados pelos outros professores. Mesmo possuindo um planejamento prévio e preparando aulas para atender às necessidades dos alunos, as professoras buscam conhecer o que os outros professores estão ensinando para evitar dar o mesmo enfoque no conteúdo de sexualidade.

Conteúdo - Em seus discursos as professoras revelaram que constantemente buscam novas formas para ensinar o conteúdo como: jogos de quebra-cabeças, pinturas com uso de tinta escolar, dramatizaçôes, caixinhas de perguntas, uso de gravuras, projeção de filmes, jogos variados, concursos de melhor frase ou desenho, entre outras. Elas valorizam o uso desse material, pois sabem que, trabalhando com o conteúdo de sexualidade de uma forma mais lúdica, fica mais fácil para o aluno participar sem sentir-se constrangido. Os discursos também apontam que as professoras descobriram que podem tratar o conteúdo de sexualidade numa abordagem interdisciplinar fazendo uso de textos, explorando as gravuras dos livros didáticos ou mesmo trabalhando as situações que surgem no meio de uma aula como, por exemplo, quando algum aluno leva uma revista pornográfica para a sala de aula ou quando eles fazem brincadeiras no momento em que uma palavra como cobra, perereca, introduzir, dar e enfiar, entre outras, é pronunciada pela professora durante uma explicação. Além disso, elas também descobriram que vão aprendendo a trabalhar com o conteúdo a partir dos erros e das perguntas dos alunos. Dessa forma, vão aprendendo enquanto ensinam, pois uma pergunta para a qual não possuem respostas as leva, conseqüentemente, a estudar mais.

Formação contínua - Os discursos mostram que as professoras participam de grupos de estudos, de reuniōes e de oficinas. As convergências apontam que as três atribuem um grande valor à teoria e acreditam que as aulas podem ser melhoradas a partir da aprendizagem que elas adquirem nos encontros e nas palestras que freqüentam. Elas também valorizam as informaçôes que podem ser adquiridas no meio extra-acadêmico como as conversas informais 
com os profissionais da área de saúde. $\mathrm{Na}$ fala das professoras fica evidente que, à medida que elas começaram a trabalhar com a sexualidade como conteúdo, foram surgindo questôes que as direcionavam para a busca de literatura especializada, pois esse tema tem uma abrangência muito ampla e elas sentiram que precisavam ter um bom conhecimento do conteúdo para continuarem atuando como educadoras sexuais, uma vez que a confiança do aluno na professora está relacionada, também, ao fato de que ela, teoricamente, possui um conhecimento mais amplo que o dele sobre sexualidade.

Avaliação - Na convergência dos discursos, todas as professoras demonstraram que estão, constantemente, realizando avaliação nas aulas. Nesse tipo de conteúdo não existe atribuição de notas para o aluno, porém as mudanças que se vão expressando no comportamento do grupo como, por exemplo, alunos que deixam de lado as brincadeiras de passar a mão no corpo do outro, que param de escrever nas portas dos banheiros e os que falam sobre sexualidade de forma natural, sem risadinhas ou tentativas de esconder o rosto, são mudanças avaliadas como positivas pelas professoras. Essas observações, assim como os trabalhos e a participação dos alunos em sala de aula, são anotadas por elas e auxiliam no momento de avaliação do projeto.

\section{Sociedade: modelos, implicaçôes...}

Modelos - As convergências dos discursos mostram que os alunos buscam modelos para seguirem e observam tudo o que as professoras fazem. Encontramos uma divergência em um dos discursos em que a professora gosta de ser modelo para os alunos, pois sabe que eles sempre observam o comportamento dela. Os outros discursos mostram que as professoras não gostam de ser modelos para os alunos e explicam-lhes que eles devem refletir sobre a própria vida a partir das discussóes que surgirem nos debates e decidir por um caminho a seguir, já que todos eles possuem experiências e vivências diferentes e cada um tem sua própria identidade.

Implicações - Em todos os discursos, as professoras expressam a necessidade de estar bem com a própria sexualidade para falar sobre esse tema com os alunos. Essa é uma necessidade imposta pelo próprio conteúdo para evitar que, de um momento para o outro, elas assumam posturas pessoais perante uma classe que esteja discutindo um assunto polêmico ou não, como a legalização do aborto. Se em algum momento da vida, uma professora vivenciou uma situação de aborto e ficou com traumas que não foram superados, quando esse assunto surgir em uma classe, possivelmente, ela terá uma dificuldade maior para lidar com essa questão sem deixar transparecer seus sentimentos ou manifestar sua opinião pessoal. As convergências apontam que as professoras têm como objetivo maior trabalhar as questôes da sexualidade como forma de prevenção para problemas na vida dos alunos. Entretanto, isso exige muita responsabilidade, pois elas sabem que o aluno adolescente é muito vulnerável e sabem, também, que o fato de ensinar um aluno a se proteger de possíveis doenças ou mesmo de problemas relacionados à sexualidade proporciona a ele uma certa autonomia que pode influenciar a decisão de iniciar ou não a sua vida sexual ativa. Todas as professoras afirmam que esse risco existe, porém acreditam que o aluno bem informado poderá tomar melhores decisões. Os discursos ainda apontam que as professoras estão constantemente refletindo sobre sua prática no sentido de aperfeiçoá-la, conscientes de que sabem que as aulas são um importante mecanismo para provocar mudanças na sociedade.

\section{A voz das professoras e a literatura}

A partir do momento em que se inicia o ensino do conteúdo de sexualidade, surge, paralelamente, a necessidade de buscar formas mais adequadas para o ensino desse conteúdo 
devido às particularidades que ele impõe. Assim, as professoras revelaram estar constantemente buscando integrar o conteúdo com estratégias adequadas. Essa não é uma prática recente e nem se aplica especificamente a esse conteúdo. Verificamos que, durante muito tempo, o conteúdo disciplinar e a pedagogia formavam um todo, não havendo distinção entre conhecimento do conteúdo e método pedagógico. Isso aconteceu durante a transição da Idade Média para a Idade Moderna, séc. XVI, quando Comênio propôs um "método único de ensinar tudo a todos". Ele imaginou que esse método único de ensino poderia "ensinar tudo a todos" de uma maneira rápida e eficiente (MARTINS, 1996, p. 80).

A partir da segunda metade do século XX, verificamos que houve um grande aumento de pesquisas em educação. Em uma entrevista com professores experientes e novatos, Leinhartdt e outros pesquisadores da Universidade de Pittsburgh (apud GROSSMAN et al., 1989) relataram que os professores experientes, ao contrário dos professores novatos, exibiram estrutura hierárquica maior de seus conhecimentos, sugerindo a importância de profundidade e organização no conhecimento de conteúdo para o ensino. Essa questão da experiência ao longo dos anos de ensino possibilita que os professores façam relações de suas disciplinas com outros temas que surgem no contexto escolar, ou mesmo, proporciona uma certa facilidade para que eles se lancem em busca de novos conhecimentos, extrapolando os limites de sua área de formação. Particularmente em relação ao conteúdo de sexualidade, verificamos que as professoras dispuseram-se a aceitar o desafio de aprender e ensinar esse conteúdo, principalmente por possuírem uma crença de que essa seria uma tarefa relativamente fácil, uma vez que elas poderiam utilizar o conhecimento adquirido com a experiência em ensino.

Recentemente, pesquisas em educação começam a incluir investigações na compreensão dos conhecimentos que o professor possui. Shulman $(1986$, p. 9) aponta três categorias do conhecimento de conteúdo: Conhecimento de Conteúdo Específico, Conhecimento Pedagógico do Conteúdo e Conhecimento Curricular. Essas categorias influenciam no modo como o conhecimento cresce na mente dos professores. Discutiremos mais detalhadamente sobre o Conhecimento Pedagógico do Conteúdo.

Ressaltamos que, na prática dos professores, não se pode apontar um limite bem definido para esse tipo de conhecimento, como é apresentado na literatura, uma vez que o Conhecimento Pedagógico do Conteúdo completa e envolve os outros tipos de conhecimento. Shulman (1986, p. 9) diz que o Conhecimento Pedagógico do Conteúdo é um tipo de conhecimento que ultrapassa o da disciplina, por si, constituindo um conhecimento da disciplina para o ensino. Além de incluir as mais poderosas analogias, explicações e demonstrações, exemplos, maneiras de representar e formular a disciplina de forma que seja compreensível aos outros, ele também inclui o entendimento do que faz a aprendizagem de determinado tópico fácil ou difícil, os conceitos e preconceitos que estudantes de diferentes idades e origens trazem consigo para a aprendizagem daquelas lições e tópicos mais freqüentemente ensinados.

Segundo Doster et al. (1997, p. 53), “o Conhecimento Pedagógico do Conteúdo tem sido aproveitado por alguns educadores em ciências e pesquisadores educacionais” (e.g., Krajcik \& Borko, 1991, apud DOSTER et al. 1997), "como um útil instrumento de organização, numa expressão elegante de noções as quais têm levado antecipadamente, pouco a pouco, a uma reflexão prática do ensino de ciências e da educação do professor". Cochran \& Jones (1998, p. 713-4) dizem que "o entendimento atual das relações entre Conteúdo e Conhecimento Pedagógico tem sido desenvolvido pela idéia teórica de Conhecimento Pedagógico do Conteúdo" (Cochran, DeRuiter \& King 1993, Kennedy 1990, Shulman 1986, 1987, apud COCHRAN \& JONES, 1998). "O Conhecimento Pedagógico do Conteúdo é descrito como um entendimento integrado diferente de ambos, Conhecimento do Conteúdo ou Conhecimento Pedagógico.” 
Sobre professores sem experiência, Cochran \& Jones (1998, p. 714) afirmam que "eles têm níveis menos completos de Conhecimento Pedagógico do Conteúdo e as conexões entre Conhecimento do Conteúdo e Conhecimento Pedagógico ficam muito mais claras, sofisticadas e complexas com experiência de ensino" (e.g., Ball \& McDiarmid 1990; Feiman-Nemser \& Parker 1990; Wilson 1992, apud COCHRAN \& JONES, 1998). Os autores citam ainda, a necessidade de "trabalhos teóricos para desenvolver hipóteses sobre as dimensões, segundo as quais o Conhecimento Pedagógico do Conteúdo possa ser diferenciado do Conhecimento do Conteúdo Específico ou do Conhecimento Pedagógico em termos de seu desenvolvimento, estrutura, conteúdo e uso".

Verificamos que à medida que as professoras vão conhecendo o conteúdo de Sexualidade, elas começam a organizá-lo de maneira a torná-lo mais acessível ao aluno, ou seja, as professoras transformam o conteúdo, criando representações com a finalidade de ensinar, a partir das interações que surgem na sua prática. Durante as aulas, é possível acontecer a vivência de teatros, debates, o uso de artigos para subsidiar a realização de trabalhos, a exibição de filmes e várias outras formas que elas supõem serem adequadas ao conteúdo ensinado. É na tentativa de acertar a melhor forma de ensinar que elas cometem erros, porém existe reflexão sobre esses erros e eles são considerados no planejamento de novas aulas. De acordo com Carvalho (2001), quando os professores planejam uma aula, existem vários momentos nos quais eles podem aprimorar o seu Conhecimento Pedagógico do Conteúdo. Nesses momentos, os professores podem usar o feedback dos alunos para reorientar seus objetivos e suas estratégias. A troca de experiências, bem como a literatura na área de ensino e a formação continuada, também são artifícios dos quais o professor pode lançar mão para desenvolver o seu Conhecimento Pedagógico do Conteúdo.

\section{Olhando os horizontes}

O caminho percorrido em busca de uma aproximação à compreensão do fenômeno Desenvolvimento do Conhecimento Pedagógico do Conteúdo de Sexualidade levou-nos à descrição das professoras sobre a experiência em trabalhar com esse conteúdo. A partir da análise do discurso, foi possível definir a estrutura dessa experiência e desvelar os significados atribuídos pelas professoras para a construção do ensino de Sexualidade.

$\mathrm{O}$ discurso das três professoras revela, em algum grau, a forma pela qual ocorre o desenvolvimento profissional na escola. Ao dizerem sobre o interesse de assumirem uma disciplina com enfoque principal em sexualidade, elas revelaram que esse interesse relaciona-se ao reconhecimento das necessidades evidenciadas pelos alunos de discutirem sobre sexualidade e, também, à crença de que esse conteúdo ajudará na formação de indivíduos capazes de tomadas de decisões adequadas a um desenvolvimento biopsicossocial saudável. Outro aspecto que também as influenciou a ensinarem esse conteúdo foi a disposição para um repensar de suas próprias vidas. Assim, mesmo sem possuir uma formação específica para o ensino de tal conteúdo, elas vislubraram a possibilidade de ministrar aulas eficazes devido à experiência de ensino que já possuíam.

Quando as professoras começam a trabalhar com o conteúdo de Sexualidade, elas vão sentindo que é preciso ampliar o conhecimento específico sobre esse tópico. Então, os encontros que acontecem em horário extra-turno, passam a ser uma grande oportunidade para aprendizagem, pois elas têm a possibilidade de trocar experiências, participar de palestras, obter informações sobre bibliografias ou eventos. Elas revelaram, também, que estudam em livros e revistas especializadas e buscam informações com profissionais da área de saúde. Essa necessidade de aprofundar o conhecimento de conteúdo surge a partir dos desafios que o próprio 
tema impõe para os professores que com ele trabalham. Esses desafios aparecem a todo instante tanto nas perguntas dos alunos para as quais as professoras não possuem respostas, quanto nas situaçôes que surgem na sala de aula e as professoras não sabem como resolver. Elas sabem que o amplo conhecimento do conteúdo as ajuda a estabelecer relações entre os temas abordados dentro do conteúdo de Sexualidade e até mesmo com os temas abordados em outras disciplinas.

As três professoras apontam uma preocupação em preparar o aluno para a vida. Nesse sentido, elas se preocupam em oferecer possibilidades aos alunos para reavaliarem seus valores, repensarem os preconceitos existentes na sociedade e reconhecerem as formas de prevenção para problemas futuros. Elas atribuem um grande valor àquilo que os alunos vivenciam em sala de aula e, mais ainda, àquilo que o aluno pratica na escola e fora dela após as reflexões e os debates que acontecem durante as aulas. Desse modo, as professoras buscam alternativas que lhes possibilitem fazer a transformação do conteúdo de Sexualidade em conteúdo de ensino. Essa é uma busca interminável, uma vez que, em cada aula, existe a possibilidade de surgirem novas idéias e metodologias que melhor se adequam ao conteúdo. Assim, ao mesmo tempo em que ocorre o aprofundamento do conhecimento de conteúdo, vai acontecendo, também, o aprofundamento do conhecimento pedagógico e, conseqüentemente, o do conhecimento de metodologias mais adequadas a determinados conteúdos. Isso significa que as professoras têm a oportunidade de desenvolverem o Conhecimento Pedagógico do Conteúdo a partir da própria vivência.

A constatação de que as oportunidades de desenvolvimento profissional nunca se esgotam sugere que o professor nunca dominará totalmente sua trajetória, necessitando estar em constante busca de novos caminhos a seguir. Assim, visualizamos a necessidade de repensar os cursos de formação de professores, particularmente, repensar sobre o preparo que o futuro professor recebe durante sua formação inicial, para enfrentar situaçôes novas ou desconhecidas, como o ensino de Sexualidade, no momento em que ele se tornar mais um dos profissionais da educação. Em uma outra perspectiva, vislumbramos a necessidade de reflexões que envolvam familiares e agentes da sociedade que também atuam como educadores sexuais, visto que o reflexo dessa educação incide na escola e não deve ser desvinculado dela.

\section{Referências}

BARCELOS, N. S. et al. Educação sexual: relato de uma experiência. Revista Brasileira de Sexualidade Humana, São Paulo, v. 7, p. 150-160, 1996. Edição especial 2.

CARVALHO, W. L. P. O ensino de ciências sob a perspectiva da criatividade: uma análise fenomenológica. 1991. 302 f. Tese (Doutorado) - Faculdade de Educação, Universidade Estadual de Campinas, Campinas, 1991.

CARVALHO, W. L. P. Physics teachers and their knowledge of physics teaching. In: ARIAV, T.; KEINAN, A.; ZUZOVSKY, R. (Org.). The ongoing development of teacher education: exchange of ideas. Tel Aviv: The MOFET Institute, 2001. v. 1, p. 247-259.

CHAUÍ, M. H. A repressão sexual: essa nossa desconhecida. 8. ed. São Paulo: Brasiliense, 1985. 234 p.

COCHRAN, K. F.; JONES, L. The subject matter knowledge of preservice science teachers. In: FRASER, B. J.; TOBIN, K. G. (Ed.). International handbook of science education. London: Kluwer Academic Publishers, 1998. p. 707-718. 
DOSTER, E. C.; JACKSON, D. F.; SMITH, D. W. Modeling pedagogical content knowledge in physical science for prospective middle school teachers: problems and possibilities. Teacher Education Quarterly, Claremont, v. 24, n. 4, p. 51-65, 1997.

GARNICA, A. V. M. Algumas notas sobre pesquisa qualitativa e fenomenologia. Interface: Comunicação, Saúde, Educação, Botucatu, v. 1, n. 1, p. 117, 1997.

GROSSMAN, P.; WILSON, S.; SHULMAN, L. Teacher of substance: subject-matter knowledge for teaching. In: REYNOLDS, M. (Ed.). Knowledge base for the beginning teacher. New York: Perganon, 1989. p. 23-36.

LORENCINI-JUNIOR, A. Os sentidos da sexualidade: natureza, cultura e educação. In: AQUINO, J. G. (Coord.). Sexualidade na escola: alternativas teóricas e práticas. São Paulo: Summus, 1997. p. 95.

MARTINS, J.; BICUDO, M. A. V. B. A pesquisa qualitativa em psicologia: fundamentos e recursos básicos. São Paulo: Moraes, 1989. p. 22.

MARTINS, P. L. O. A relação conteúdo-forma: expressão das contradições da prática pedagógica na escola capitalista. In: VEIGA, I. P. A. et al. Didática: o ensino e suas relações. 2. ed. Campinas: Papirus, 1996. p. 80.

RIBEIRO, H. C. F. Orientação sexual e deficiência mental: estudos acerca da implementação de uma programação. 1995. 406 p. Tese (Doutorado) - Instituto de Psicologia, Universidade de São Paulo, São Paulo, 1995.

SAYÃO, R. Orientação sexual na escola: os territórios possíveis e necessários. In: AQUINO, J. G. (Coord.). Sexualidade na escola: alternativas teóricas e práticas. São Paulo, Summus, 1997. 144 p.

SHULMAN, L. S. Those who understand: knowledge growth in teaching. Educational Researcher, Washington, v. 15, n. 2, p. 4-14, 1986.

WEREBE, M. J. G. Sexualidade, política, educação. Campinas: Autores Associados, 1998. 217 p.

VITIELLO, N. Reprodução e sexualidade. Um manual para educadores. São Paulo: CEICH, 1994. p. 209 